SS. Involvement of p38 MAPK in the up-regulation of tissue factor on endothelial cells by antiphospholipid antibodies. Arthritis and rheumatism. 2005;52(5):1545-54.

Disclosure of Interest: None declared

DOI: 10.1136/annrheumdis-2017-eular.5880

\title{
THU0238 P-GLYCOPROTEIN MONOCLONAL ANTIBODY IMPROVES LUPUS-LIKE SYNDROME IN MRL/LPR MICE
}

M. Wang, P. Zeng, G. Zhou, J. Lv, Q. Wang. Department of Rheumatology and Immunology, Peking University Shenzhen Hospital, Shenzhen, Guangdong 518036, CHINA., Shenzhen, China

Background: Preventing steroid resistance and maintaining disease control are significant challenges to overcome in treating SLE patients ${ }^{[1]}$. P-glycoprotein (P-gp) of membrane transporters, a product of the multiple drug resistance (MDR)-1 gene, is known to play a pivotal role in the acquisition of drug resistance to chemotherapy in autoimmune diseases ${ }^{[2]}$.Inhibition of P-gp could overcome such drug resistance ${ }^{[3,4]}$. So we observed the effect of P-gp monoclonal antibody on MRL/lpr lupus mice.

Objectives: To investigate the efficacy of P-glycoprotein monoclonal antibody in the treatment of the MRL/lpr mice.

Methods: Twenty four 14- week- old MRL/lpr female mice were divided into 3groups:group 1 (G1)were treated with P-glycoprotein monoclonal through caudal vein, group 2 (G2)were treated with P-glycoprotein monoclonal three times and group $0(\mathrm{G} 0)$ were treated with $0.5 \mathrm{ml}$ normal saline as controls. Twenty-four hours proteinuria and body weight were assessed every two weeks.Enzyme linked immunosorbent assay (ELISA)was used to measure the levels of serum anti-dsDNA antibodies. The histopathology changes of the kidneys were observed.

Results: From the 22th week,the body weight of groups Gl and G2 increased significantly than that of the group G0 $(p<0.05)$. At the 22th weeks, the 24 hours proteinuria in group $\mathrm{Gl}(1.9 \pm 1.1) \mathrm{mg}$ and $\mathrm{G} 2(1.4 \pm 0.9) \mathrm{mg}$ was decreased than that in group G0 $(3.1+1.9) \mathrm{mg}(p<0.05)$, and at the 26 th weeks, that of groups $\mathrm{G} 1(2.4 \pm 1.4) \mathrm{mg}$ and $\mathrm{G} 2(1.8 \pm 1.1) \mathrm{mg}$ was also significantly decreased than in group G0 $(5.3 \pm 2.2) \mathrm{mg}(p<0.01)$. At week 26 , serum creatinine decreased significantly in both groups G1 (7.0 \pm 2.9$) \mathrm{umol} / \mathrm{L}$ and $\mathrm{G} 2(6.1 \pm 2.5) \mathrm{umol} / \mathrm{L}$ than in group G0 (12.7 \pm 1.3$)$ umol/L $(p<0.05)$. One week after treatment, the levels of anti-dsDNA antibodies in group Gl $(43 \pm 19) \times 10^{2} \mathrm{U} / \mathrm{ml}$ and $\mathrm{G} 2(45 \pm 32) \times 10^{2} \mathrm{U} / \mathrm{ml}$ were both significantly decreased than those of the group G0 $(87 \pm 39) \times 10^{2} \mathrm{U} / \mathrm{ml}$ $(p<0.05)$, and at the 26th weeks the difference between group G2 $(35 \pm 11) \times 10^{2}$ $\mathrm{U} / \mathrm{ml}$ and $\mathrm{GO}(59 \pm 35) \times 10^{2} \mathrm{U} / \mathrm{ml}$ was statistically significant. The nephron crescent formation in group G1 $(0.11 \pm 0.05)$ and G2 $(0.09 \pm 0.01)$ was significandy lower that

Table 1. Effects of P-gp monoclonal antibody on the levels of anti-dsDNA antibodies, serum creatinine and the routine blood test of MRL/lpr mice (' $\mathrm{X} \pm \mathrm{s}$ )

\begin{tabular}{lcccccc}
\hline Group & Number & $\begin{array}{c}\text { ds-DNA } \\
\left(\times 10^{2} \mathrm{U} / \mathrm{ml}\right)\end{array}$ & $\begin{array}{c}\text { Scr } \\
(\mu \mathrm{mol} / \mathrm{ml})\end{array}$ & $\begin{array}{c}\text { WBC } \\
\left(\times 10^{9} / \mathrm{L}\right)\end{array}$ & $\begin{array}{c}\mathrm{HB} \\
(\mathrm{g} / \mathrm{L})\end{array}$ & $\begin{array}{c}\mathrm{PLT} \\
\left(\times 10^{9} / \mathrm{L}\right)\end{array}$ \\
\hline G1 & 8 & $48 \pm 19$ & $8.3 \pm 2.4^{*}$ & $7.8 \pm 3.6^{*}$ & $124 \pm 8$ & $118 \pm 97^{*}$ \\
G2 & 8 & $35 \pm 11^{\#}$ & $6.1 \pm 3.5^{\#}$ & $5.9 \pm 4.2^{\#}$ & $138 \pm 13$ & $132 \pm 85^{\#}$ \\
G0 & 8 & $59 \pm 35$ & $13.2 \pm .8$ & $3.1 \pm 2.9$ & $110 \pm 11$ & $76 \pm 61$ \\
\hline
\end{tabular}

Notes: *G1 vs G0 $p<0.05$, \# G2 vs G0 $p<0.05$.

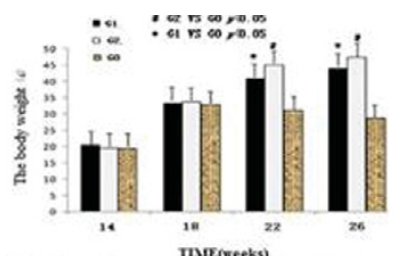

minereeks)

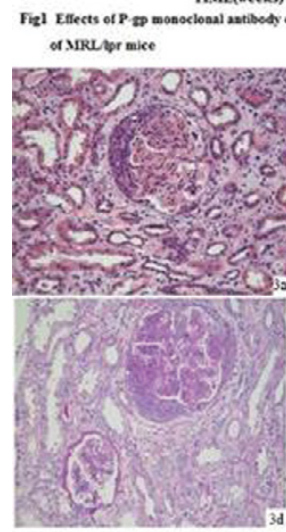

rig3 Effoct of $\mathbf{P}$ gp monoclonal antibody oa renal pattologs in MRL /pr mice

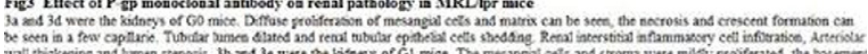

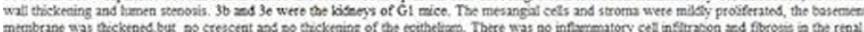

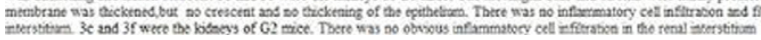

of the group $\mathrm{G} 0(0.23 \pm 0.07)(p<0.05)$, and that of group $\mathrm{G} 2$ was significantly less that of group $\mathrm{Gl}(p<0.05)$.

Conclusions: P-glycoprotein monoclonal antibody is very effective in treating $\mathrm{MRL} / \mathrm{lpr}$ mice.It is safe and free of rejection reactions.

References:

[1] Barnes PJ.Mechanisms and resistance in glucocorticoid control of inflammation. J Steroid Biochem Mol Biol. 2010,120(2-3):76-85.

[2] García-Carrasco M, Mendoza-Pinto C, Macias Díaz S, et al. P-glycoprotein in autoimmune rheumatic diseases.See comment in PubMed Commons belowAutoimmun Rev.2015,14(7):594-600.

[3] Advani R, Visani G, Milligan D, Saba H, Tallman M, Rowe JM,et al. Treatment of poor prognosis AML patients using PSC833 (valspodar) plus mitoxantrone, etoposide, and cytarabine (PSC-MEC). Adv Exp Med Biol. 1999,457:47-56.

[4] Fisher GA, Lum BL, Hausdorff J, Sikic BI. Pharmacological considerations in the modulation of multidrug resistance. Eur J Cancer. 1996,32A(6):1082-1088.

Acknowledgements: We thank prof. Guofeng GAO's assistance in editing the manuscript.

Disclosure of Interest: M. Wang Grant/research support from: NO, P. ZENG Consultant for: NO, G. ZHOU Employee of: NO, J. LV Paid instructor for: NO, Q. WANG Grant/research support from: NO, Speakers bureau: NO

DOI: 10.1136/annrheumdis-2017-eular.1730

\section{THU0239 SERUM HMGB1 AND TLR4 LEVELS AS NOVEL BIOLOGICAL MARKERS FOR THE ACTIVITIES OF NEUROPSYCHIATRIC SYSTEMIC LUPUS ERYTHEMATOSUS}

Q. Huang ${ }^{1}$, C. Yuan ${ }^{2}, \mathrm{H}$. Ren ${ }^{1}$, M. Yang ${ }^{1}$. ${ }^{1}$ Department of Rheumatology; ${ }^{2}$ Department of Neurology, Nanfang Hospital, Southern Medical University, Guangzhou, China

Background: Neuropsychiatric Systemic Lupus Erythematosus (NPSLE) is a severe complication of SLE, including a variety of neurological and psychiatric features. Previous studies have demonstrated the close relationship between NPSLE and inflammation. HMGB1-TLR4 signaling pathway is the up-stream pathway of $\mathrm{NF}-\kappa \mathrm{B}$, which could upregulate the expression of various cytokines and other inflammatory mediators.

Objectives: The objective of the study was to explore the potential mechanism of HMGB1-TLR4 axis in SLE.

Methods: The study population consisted of 107 SLE patients and 43 ageand sex-matched healthy controls. 73 SLE patients had active disease. 36 of these had NPSLE. The serum anti-NR2A antibodies levels were measured by ELISA. Clinical and serological parameters were assessed according to routine procedures. HMGB1 and TLR4 levels were measured by ELISA.Statistical analyses were performed by using the chi-square test and the t-test.

Results: CNS manifestations accounted for 94\% (34/36 patients), while involvement of the PNS was $6 \%(2 / 36$ patients). The majority of the manifestations were Seizure disorders ( $n=17 ; 47.2 \%)$, Headache $(n=12 ; 33.3 \%)$, Cognitive dysfunction $(n=10 ; 27.8 \%)$, Psychoses $(n=8 ; 22.2 \%)$. Within the group of active patients those with NP manifestations had higher HMGB1 levels $(0.451) 0.292$ to $0.583)$ ) compared to active patients with non-NP manifestations $(0.356$ (0.098 to $0.436))$. In patients with NP $(0.429(0.313$ to 0.526$))$ and non-NP $(0.375$ (0.196 to 0.478)) manifestations during active periods of the disease, TLR4 levels significant increased in comparison to the controls. TLR4 levels were significantly higher in active patients $(0.401$ ( 0.196 to 0.526$)$ ) compared to quiescent patients. There was a significant positive correlation between levels of HMGB1 and TLR4 in the total patients group $(\mathrm{P}<0.0001, r=0.939)$. We observed a correlation between HMGB1 levels and SLEDAI $(P<0.0001, r=0.804)$. Also, TLR4 levels showed a significant correlation with SLEDAI $(\mathrm{P}<0.0001, r=0.809)$. HMGB1 levels correlated with anti-dsDNA levels $(P<0.0001, r=0.558)$. Similarly, TLR4 showed a correlation with anti-dsDNA levels $(P<0.0001, r=0.522)$. We observed a negative correlation in the total SLE group between C3, C4 and HMGB1 levels $(P<0.0001, r=-0.545$ and $\mathrm{P}<0.0001, \mathrm{r}=-0.270$ respective. Also, TLR4 showed a significant negative correlation with $\mathrm{C} 3$ and $\mathrm{C} 4(\mathrm{P}<0.0001, r=-0.559$ and $\mathrm{P}<0.0001, r=-0.285$ respectively). Conclusions: Our data suggest that HMGB1-TLR4 axis plays an important role in the pathogenesis of SLE as well as NPSLE.

Acknowledgements: This work was supported by The President Foundation of Nanfang Hospital, Southern Medical University (NO. 2014C009, NO.2015C021). Disclosure of Interest: None declared

DOI: 10.1136/annrheumdis-2017-eular.6410

\section{THU0240 DEFECTIVE REGULATION BY ATP-GATED IONOTROPIC P2X7 RECEPTOR DRIVES T FOLLICULAR HELPER CELL EXPANSION IN SYSTEMIC LUPUS ERYTHEMATOSUS}

$\underline{\text { R. Gualtierotti }}^{1}$, C.E. Faliti ${ }^{2,3}$, M. Gerosa ${ }^{1,4}$, F. Grassi ${ }^{3,5}$, P.L. Meroni ${ }^{1,4,6}$. ${ }^{1}$ Lupus Clinic, Division of Rheumatology, ASST G. Pini; ${ }^{2}$ Istituto Nazionale Genetica Molecolare "Romeo ed Enrica Invernizzi", Milan, Italy; ${ }^{3}$ Institute for Research in Biomedicine, Università della Svizzera Italiana, Bellinzona, Switzerland; ${ }^{4}$ DISCCO, Department of Clinical Science and Community Health; ${ }^{5}$ Department of Medical Biotechnology and Translational Medicine (BIOMETRA), University of Milan; ${ }^{6}$ IRCCS Istituto Auxologico Italiano, Milan, Italy

Background: Systemic lupus erythematosus (SLE) is a chronic autoimmune 